TECHNICAL NOTE

\title{
Effect of loading direction on the ultimate lateral soil pressure of two piles in clay
}

\author{
K. GEORGIADIS*, S. W. SLOAN $\uparrow$ and A. V. LYAMIN $\dagger$
}

\begin{abstract}
Design equations are presented for the calculation of the ultimate lateral resistance of two-pile groups in clay under a general loading direction. Analytical upper bound solutions, numerical upper and lower bound limit analyses and displacement finite-element analyses are first presented for the case of two piles loaded parallel to the pile-to-pile axis. Displacement finite-element analyses are subsequently used to calculate the ultimate lateral resistance for different directions of pile displacement. The design equations that are proposed, based on the numerical study, take account of the effect of the pile spacing, the pile-soil adhesion and the displacement or the loading direction on the ultimate lateral resistance.
\end{abstract}

KEYWORDS: clays; piles; plasticity

\section{INTRODUCTION}

The limiting lateral resistance of single piles in clay has been investigated by several researchers and has been found to increase with depth up to an ultimate value which is associated with a plane strain flow-around mechanism (Murff \& Hamilton, 1993). This ultimate lateral resistance can be calculated with the lower bound plasticity solution presented by Randolph \& Houlsby (1984), which can be considered to be exact in the idealised framework of rigid plastic limit analysis, since it is in excellent agreement with upper bound plasticity solutions for the same problem (Randolph \& Houlsby, 1984; Christensen \& Niewald, 1992; Martin \& Randolph, 2006).

Georgiadis et al. (2013) considered the case of two laterally loaded, side-by-side piles in clay using analytical upper bound calculations and numerical analysis and established the relationship, shown in Fig. 1, between the lateral bearing capacity factor $N_{\mathrm{p}}$ (ultimate load per unit length normalised with respect to the undrained shear strength and

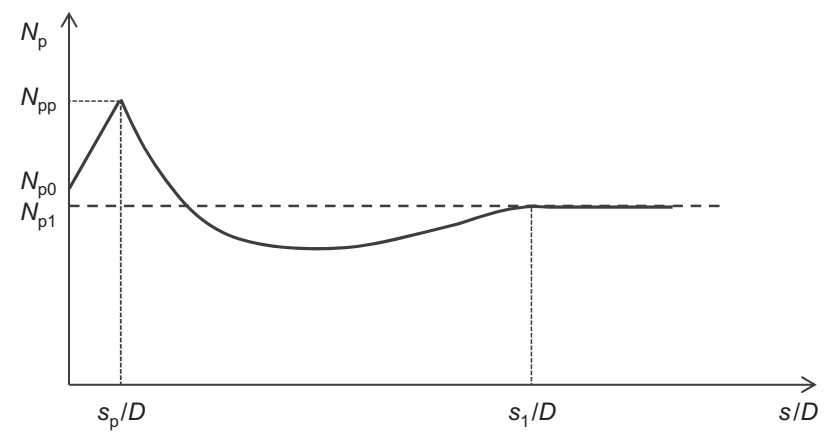

Fig. 1. $N_{\mathrm{p}}-s / D$ relationship for two side-by-side piles in clay (Georgiadis et al., 2013)

Manuscript received 31 January 2013; revised manuscript accepted 25 April 2013. Published online ahead of print 17 July 2013.

Discussion on this paper closes on 1 March 2014, for further details see p. ii.

* Department of Civil Engineering, Aristotle University of Thessaloniki, Thessaloniki, Greece. kgeorg@civil.auth.gr.

$\uparrow$ ARC Centre of Excellence for Geotechnical Science and Engineering, The University of Newcastle, NSW Australia. the pile diameter) and the normalised pile spacing $s / D$ (where $s$ is the pile spacing and $D$ is the pile diameter).

This paper presents an extension of the above study and investigates the problem of two-pile groups under a general loading direction (Fig. 2). The case of one pile in front of the other (displacement angle $\beta=0$ ) is first considered, using analytical upper bound plasticity calculations, displacement finite-element analysis and lower and upper bound finite-element analysis. Displacement finite-element analysis is subsequently employed to investigate the effect of loading direction.

\section{DETAILS OF NUMERICAL ANALYSES}

Displacement finite-element analyses were performed with the finite-element program Plaxis 2D Version 2011.02 (Brinkgreve et al., 2011). Two infinitely long cylindrical piles of diameter $D=1 \mathrm{~m}$ and centre-to-centre spacing $s$, in an infinite elastic-perfectly plastic soil medium, were displaced at an angle $\beta$, as shown in Fig. 2. A typical finiteelement mesh for a pile spacing of $s / D=2 \cdot 5$ is shown in Fig. 3. It consists of 394615 -noded triangular elements for both the piles and the surrounding soil, with interface elements placed between the piles and the soil. Similar mesh densities were employed in all analyses, while the mesh dimensions were $30 D \times 30 D$ in all cases with all four boundaries fixed in the normal direction.

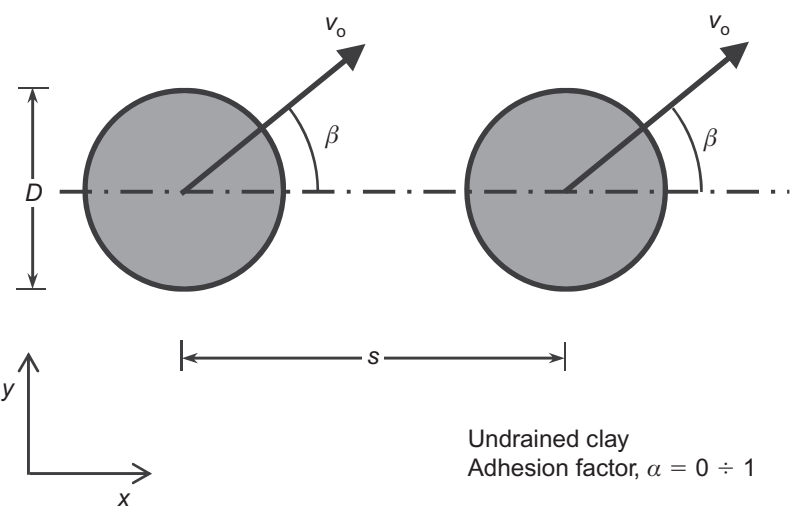

Fig. 2. Problem definition: two-pile group displaced at angle $\beta$ 


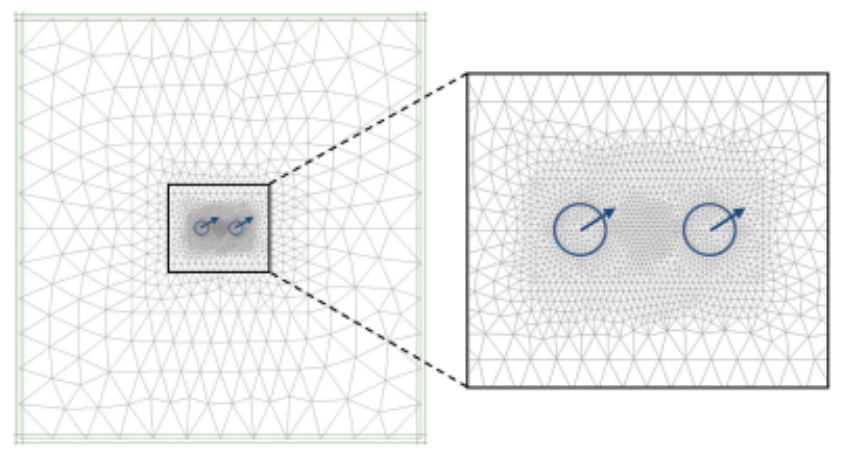

Fig. 3. Displacement finite-element mesh

The soil and pile were modelled as linear elastic-perfectly plastic and linear elastic materials, respectively, with the following properties: undrained shear strength $s_{\mathrm{u}}=100 \mathrm{kPa}$, undrained Young's modulus $E_{\mathrm{u}}=200 s_{\mathrm{u}}$, undrained Poisson ratio $v_{\mathrm{u}}=0.495$, Young's modulus of pile material $E_{\mathrm{p}}=2.9 \times 10^{7} \mathrm{kPa}$ and Poisson ratio of pile material $v_{\mathrm{p}}=0 \cdot 1$. Various pile-soil adhesion factors $\alpha \quad\left(=\tau_{\mathrm{f}} / s_{\mathrm{u}}\right.$, where $\tau_{\mathrm{f}}$ is the pile-soil adhesion) were considered for the interface behaviour. It is noted that, ideally, the two materials (pile and soil) would have been modelled as rigid and rigid-plastic, respectively. Owing to limitations of the software this was not possible; however, it was established that the calculated limit loads were independent of the elastic properties.

The majority of the displacement finite-element analyses presented in this paper were displacement-controlled. The plane strain condition considered in this study is applicable below a certain critical depth, which has been investigated for single piles in clay (Murff \& Hamilton, 1993; Klar \& Randolph, 2008; Georgiadis \& Georgiadis, 2012) and has been found to depend on the soil homogeneity (Murff \& Hamilton, 1993) and the pile-soil adhesion (Georgiadis \& Georgiadis, 2012). In addition, it was assumed in this study that the piles are connected with a perfectly rigid cap and are sufficiently rigid to displace equally at all depths. Therefore, the same displacement was applied at the pile diameter nodes of both piles (see Fig. 2). Since Plaxis can only provide the total ultimate reaction force, rather than the ultimate reaction force on each pile, this force was subsequently divided by two and used to obtain the undrained lateral bearing capacity factor $N_{\mathrm{p}}$ of each pile. In order to verify that the ultimate load is equally distributed between the two piles, a limited number of load-controlled analyses were also performed in which the same load was applied to the two piles, rather than a common displacement. Such analyses were performed for pile spacings $s / D=2$ and 3 , pile-soil adhesion factors $\alpha=0,0.5$ and 1 and several loading directions. In all analyses, the same displacements were calculated for the two piles, thus showing that the assumption of equal load distribution between the two piles in the displacement-controlled analyses is valid.

Numerical limit analyses were performed using the formulations originally developed by Sloan $(1988,1989)$ and further improved by Lyamin \& Sloan $(2002 a, 2002 b)$ and Krabbenhoft et al. (2005, 2007). Both upper and lower bound analyses were performed for the case of two piles displaced at $\beta=0$, for various normalised pile spacings $s / D$ and pile-soil adhesion factors $\alpha$. These results, combined with the results for two side-by-side piles, presented by Georgiadis et al. (2013), and the analytical upper bound solutions presented below, are used to validate the displacement finite-element model based on which a solution is proposed for general loading directions.

\section{ANALYTICAL UPPER BOUND CALCULATIONS}

Figure 4 shows two upper bound kinematic mechanisms developed for $\beta=0$. The mechanisms are geometrically symmetric about both axes and therefore only one-quarter of the mechanisms is shown.

The first mechanism (mechanism I), shown in Fig. 4(a), consists of a rigid region $\left(\mathrm{BAA}^{\prime} \mathrm{B}^{\prime}\right)$ which moves with the piles with velocity $v_{\mathrm{o}}$ along the $x$-axis, a second rigid region $\left(\mathrm{ACC}^{\prime} \mathrm{A}^{\prime}\right)$ which moves in the opposite direction with velocity $v_{\mathrm{n}}$ and a slip fan $(\mathrm{ABC})$. Two geometric parameters are required to define the mechanism: the angles $\delta$ and $\theta$.

The velocities are constant along each radius $r$ ' within the slip fan and parallel to the tangent of the outer velocity discontinuity (Fig. 4(a)). Consequently, the velocities in the slip fan $(\mathrm{ABC})$ vary only with the angle $\theta^{\prime}$. The velocity for $\theta^{\prime}=\theta$ (discontinuity $\mathrm{AB}$ ) is

$$
v=-v_{\mathrm{o}} \frac{\cos \delta}{\cos (\delta+\theta)}
$$

Based on the geometry of Fig. 4(a), the infinitesimal change in velocity within $\mathrm{ABC}$ can be expressed as

$$
\mathrm{d} v=v \tan \left(\theta^{\prime}-\psi^{\prime}\right) \mathrm{d} \theta^{\prime}
$$

Integrating equation (2) and using equation (1) to eliminate the integration constant gives the following expression for the velocity in $(\mathrm{ABC})$

$$
v=-v_{\mathrm{o}} \frac{\cos \delta}{\cos (\delta+\theta)} \frac{\sin \delta-\sin (\delta+\theta) \cos \theta}{\sin \delta-\sin (\delta+\theta) \cos \theta^{\prime}}
$$

As seen in Fig. 4(a), mechanism I does not include discontinuities along the pile-soil interface and therefore is only appropriate for perfectly rough interface behaviour $(\alpha=1)$.

In order to account for the effect of pile-soil adhesion, a second mechanism, shown in Fig. 4(b), is considered (mechanism II). This mechanism consists of translating rigid regions $(\mathrm{ABG}),\left(\mathrm{EE}^{\prime} \mathrm{B}^{\prime} \mathrm{G}^{\prime}\right)$ and $\left(\mathrm{FDD}^{\prime} \mathrm{F}^{\prime}\right)$, a stationary rigid region $\left(\mathrm{EFF}^{\prime} \mathrm{E}^{\prime}\right)$, two slip fans $(\mathrm{ABC})$ and $(\mathrm{ACDF})$ and a rigid region (AFE), which rotates about point $Y$. Five geometric parameters are required to define the mechanism: the angles $\xi$ and $\delta$, which define the rigid regions (ABG) and $\left(E^{\prime} B^{\prime} G^{\prime}\right)$, the angle $\theta_{2}$ which defines the rotating region (AFE) and the angles $\omega$ and $\theta_{1}$.

Details of the geometry of the two slip fans of this mechanism are shown in Fig. 5. The infinitesimal changes in velocity in the slip fans (ABC) and (ACDF) are

$$
\begin{aligned}
& \mathrm{d} v_{1}=v_{1} \tan \left(\theta_{1}^{\prime}-\psi^{\prime}\right) \mathrm{d} \theta_{1}^{\prime} \\
& \mathrm{d} v_{2}=v_{2} \tan \left(\theta_{2}^{\prime}-\omega^{\prime}\right) \mathrm{d} \theta_{2}^{\prime}
\end{aligned}
$$

Noting that the velocity for $\theta_{1}^{\prime}=\theta_{1}$ is given by equation (1) if $\theta$ is replaced by $\theta_{1}$, and integrating equation (4) gives

$$
v_{1}=-v_{\mathrm{o}} \frac{\cos \delta}{\cos \left(\delta+\theta_{1}\right)} \frac{R_{1} /\left(O_{1} A\right)+\cos \left(\chi+\theta_{1}\right)}{R_{1} /\left(O_{1} A\right)+\cos \left(\chi+\theta_{1}^{\prime}\right)}
$$

Integrating equation (5) and noting that $v_{2}=v_{1}$ for $\theta_{1}^{\prime}=\theta_{2}^{\prime}=\theta_{2}$

$$
\begin{aligned}
v_{2}= & -v_{\mathrm{o}} \frac{\cos \delta}{\cos \left(\delta+\theta_{1}\right)} \frac{R_{1} /\left(O_{1} A\right)+\cos \left(\chi+\theta_{1}\right)}{R_{1} /\left(O_{1} A\right)+\cos \left(\chi+\theta_{2}\right)} \\
& \times \frac{R_{2} /\left(O_{1} O_{2}\right)+\cos \theta_{2}}{R_{2} /\left(O_{1} O_{2}\right)+\cos \theta_{2}^{\prime}}
\end{aligned}
$$

The velocity within the rotating rigid body (AFE) (Fig. 4(b)) is given by 


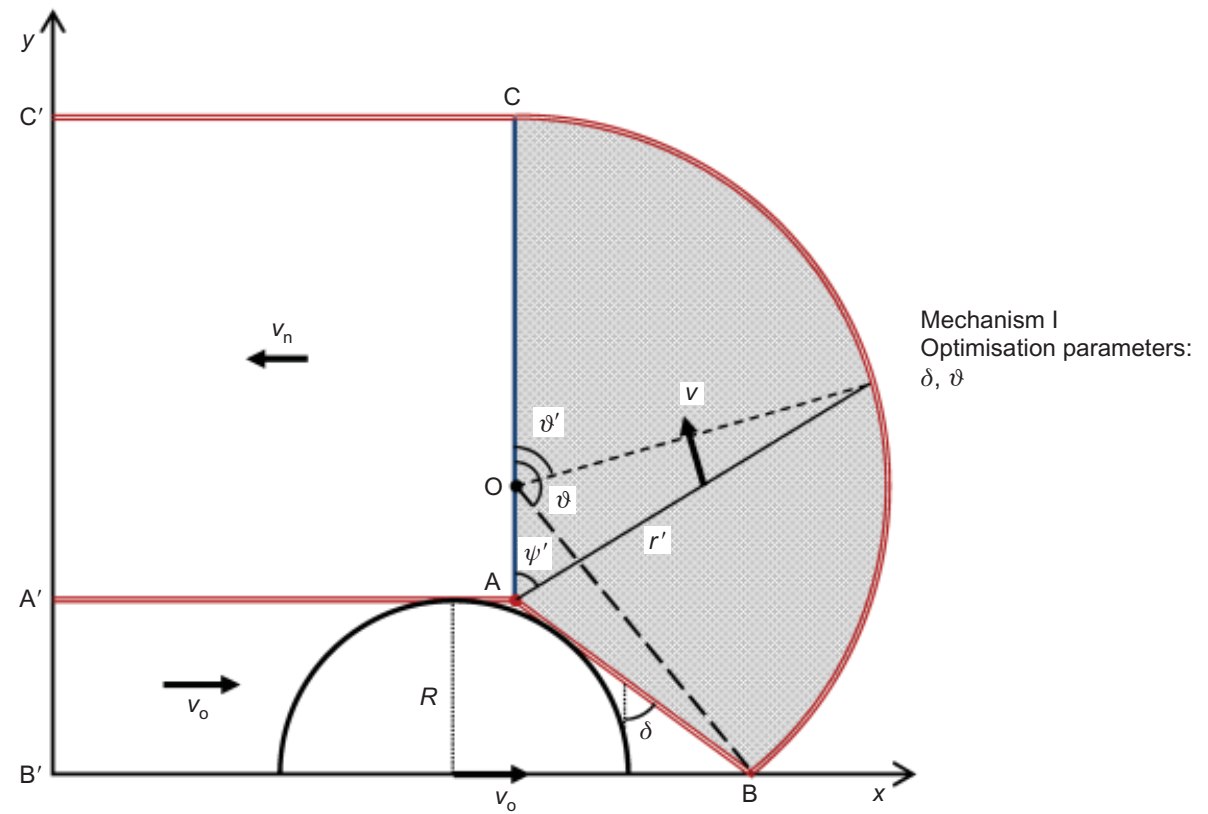

(a)

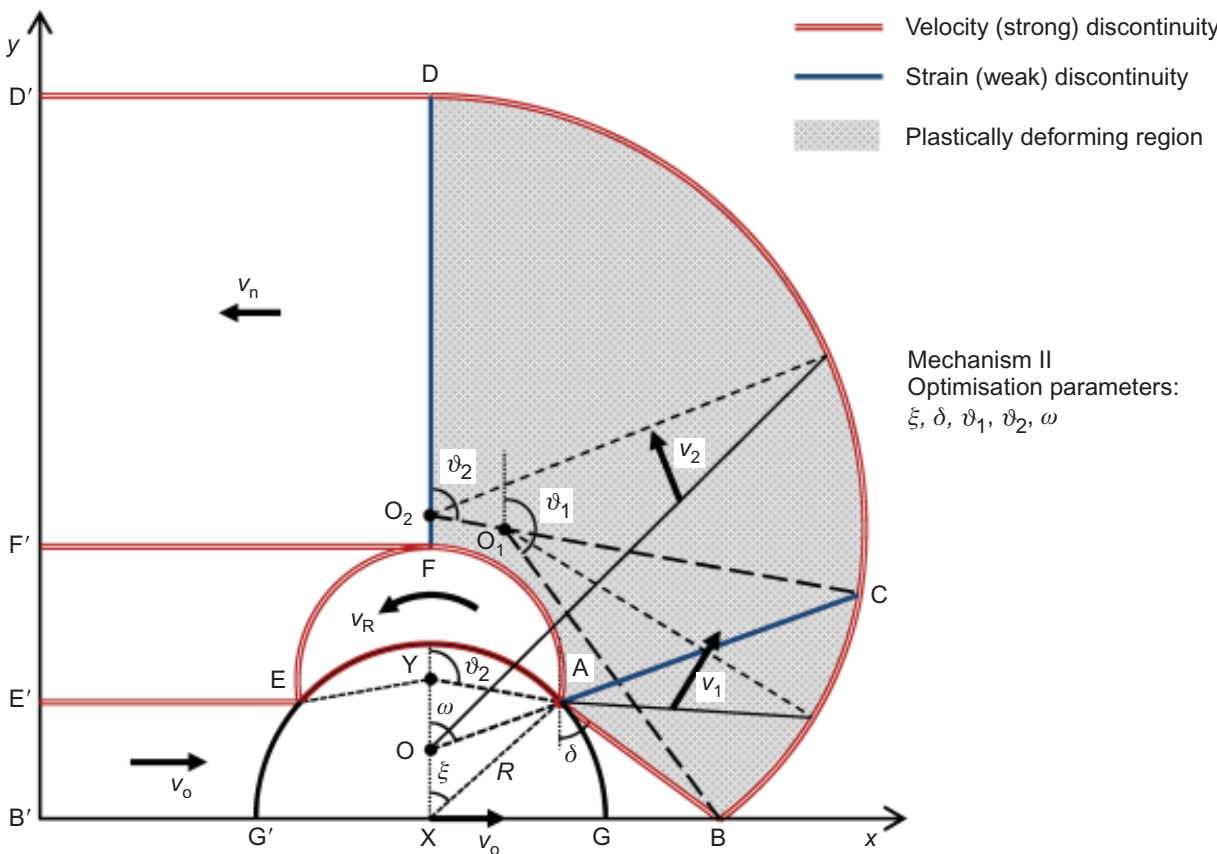

(b)

Fig. 4. Upper bound knematic mechanisms for $\beta=\pi / 2$ : (a) mechanism I; (b) mechanism II

$$
v_{\mathrm{R}}=v_{\mathrm{o}} \frac{\sin \xi}{\sin \left(\theta_{2}-\xi\right)} \frac{r}{(\mathrm{AY})}
$$

where $r$ is the radial distance from the centre of rotation Y.

The undrained lateral bearing capacity factor for each pile was calculated through the following equation

$$
N_{\mathrm{p}}=\frac{2 \Delta W_{\mathrm{p}} / v_{\mathrm{o}}}{s_{\mathrm{u}} D}
$$

where $\Delta W_{\mathrm{p}}$ is the total rate of work done by the stresses in one quarter of the mechanism (Fig. 4).

Both mechanisms were considered for the case of $\alpha=1$ and it was found that mechanism I always yielded the minimum $N_{\mathrm{p}}$ (approximately $2-3 \%$ lower than mechanism
II), whereas, as mentioned above, only mechanism II is applicable for all other values of the adhesion factor.

\section{RESULTS AND DISCUSSION}

Loading parallel to the pile-to-pile axis

Figures 6-8 show the variation of the ultimate lateral bearing capacity factor with the normalised pile spacing, obtained from the analytical upper bound calculations, the displacement and upper and lower bound finite-element analyses, for $\beta=0$ and adhesion factors $\alpha=1,0.5$ and 0 , respectively. As seen in these figures, the numerical limit analysis results provide close upper and lower bounds on the true collapse load for all cases, while the displacement finite-element results generally fall between the two bounds. Relatively good agreement is also observed between the 

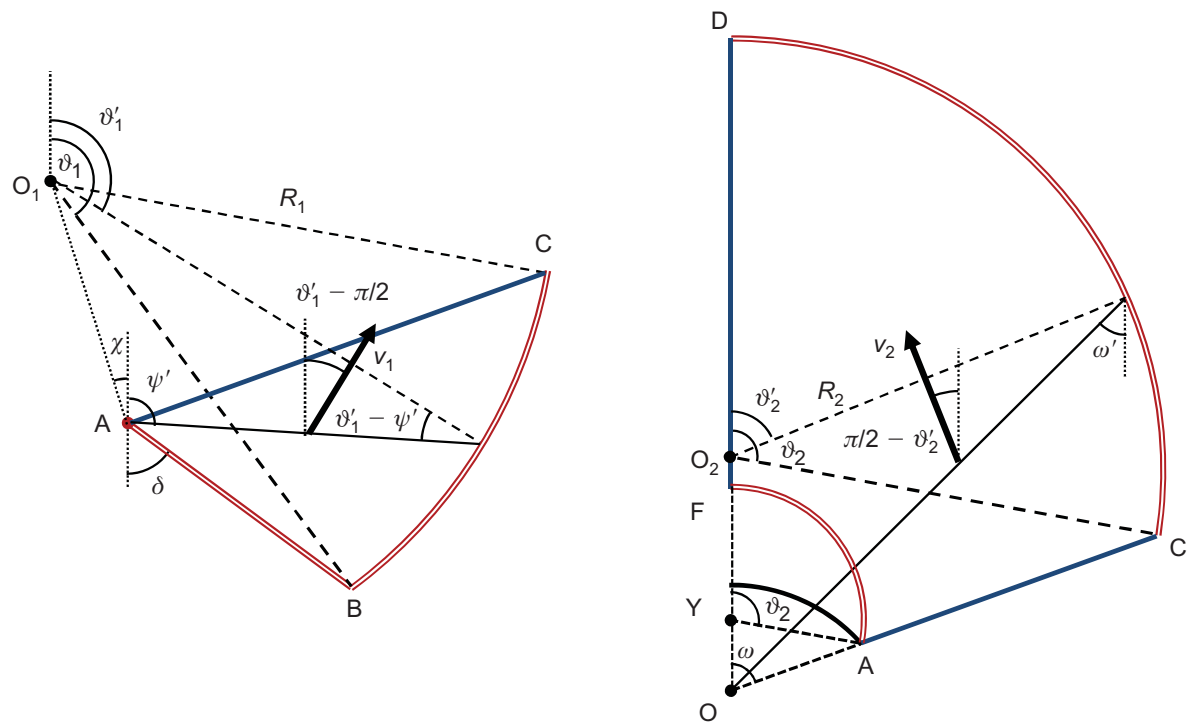

Fig. 5. Mechanism II velocities: (a) slip fan ABC; (b) slip fan CDFA

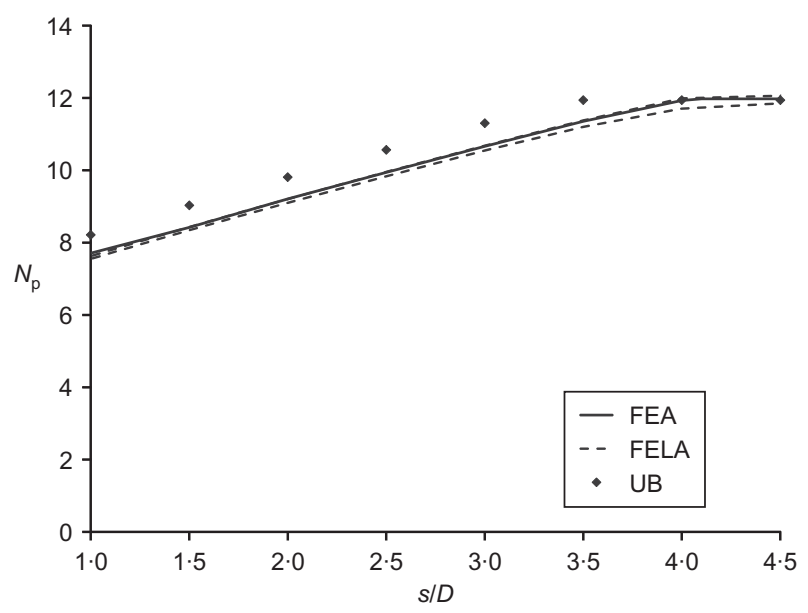

Fig. 6. Bearing capacity factor for $\alpha=1$ and $\beta=\pi / 2$ (FEA: displacement finite-element analysis; FELA: finite-element limit analysis; UB: analytical upper-bound solution)

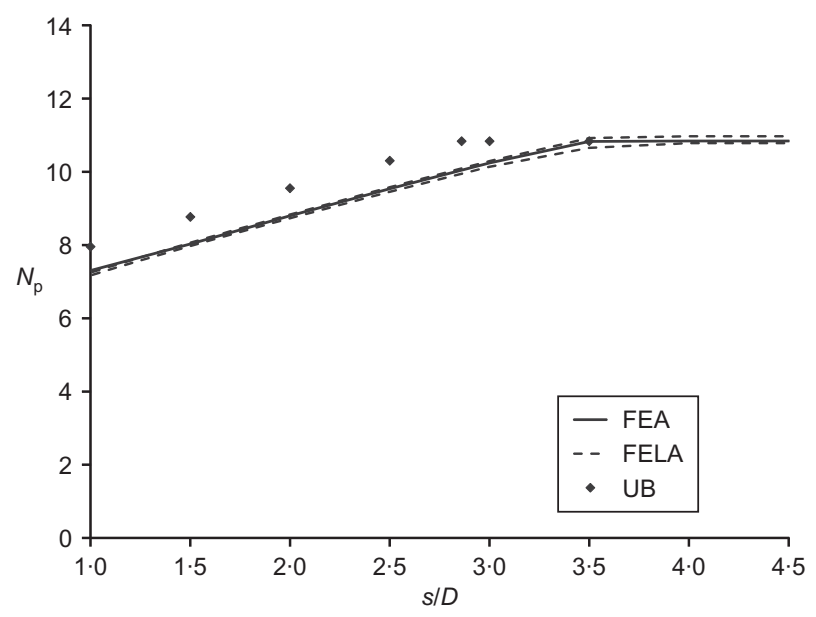

Fig. 7. Bearing capacity factor for $\alpha=0 \cdot 5$ and $\beta=\pi / 2$

analytical and numerical results. The analytical upper bound solutions provide theoretical upper bounds on the collapse load, which are between 5\% (for $\alpha=1$ and $s / D=2 \cdot 86$ ) and $11 \%$ (for $\alpha=0$ and $s / D=1$ ) higher than the displacement finite-element results, thus providing additional validation of the numerical results.

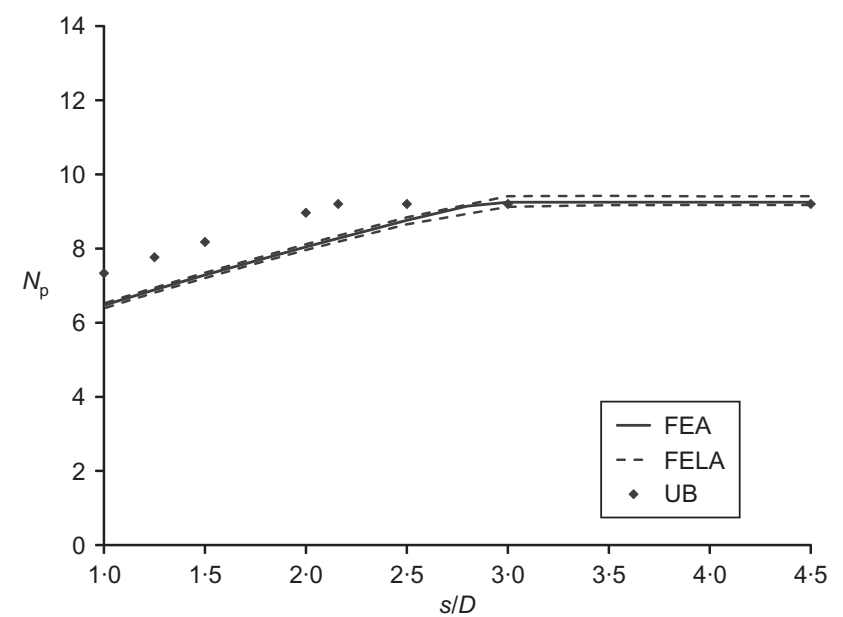

Fig. 8. Bearing capacity factor for $\alpha=0$ and $\beta=\pi / 2$

It can also be seen in Figs 6-8 that for all adhesion factors, the undrained bearing capacity factor is a minimum when the two piles are in contact $(s / D=1)$, increases almost linearly with the increase in pile spacing, and then reaches the value corresponding to a single pile at a normalised pile spacing $s_{1} / D$, which varies from approximately $s_{1} / D=3$ for $\alpha=0$ to $s_{1} / D=4$ for $\alpha=1$.

General loading direction

The effect of the displacement angle $\beta$ (Fig. 2) on the ultimate lateral capacity was investigated through a series of displacement finite-element analyses. Figs 9-11 illustrate the calculated variations of $N_{\mathrm{p}}$ with $s / D$ for three adhesion factors $\alpha=1,0.5$ and 0 , respectively. The behaviour for $\beta=\pi / 2$, which exhibits a peak capacity at a small pile spacing (Georgiadis et al., 2013), can also be observed for smaller displacement angles. As $\beta$ tends to zero this peak gradually disappears and the $N_{\mathrm{p}}-S / D$ curve becomes almost linear at $\beta=\pi / 2$. It can also be seen that the pile spacing $s_{1} / D$, at which the single pile capacity is obtained, varies with $\beta$. The minimum value of $s_{1} / D$ is observed at intermediate values of $\beta$.

The ultimate lateral capacity factors presented in Figs 9-11 can be calculated from the equations proposed by Georgiadis et al. (2013) for the case of two side-by-side piles $(\beta=\pi / 2)$ 


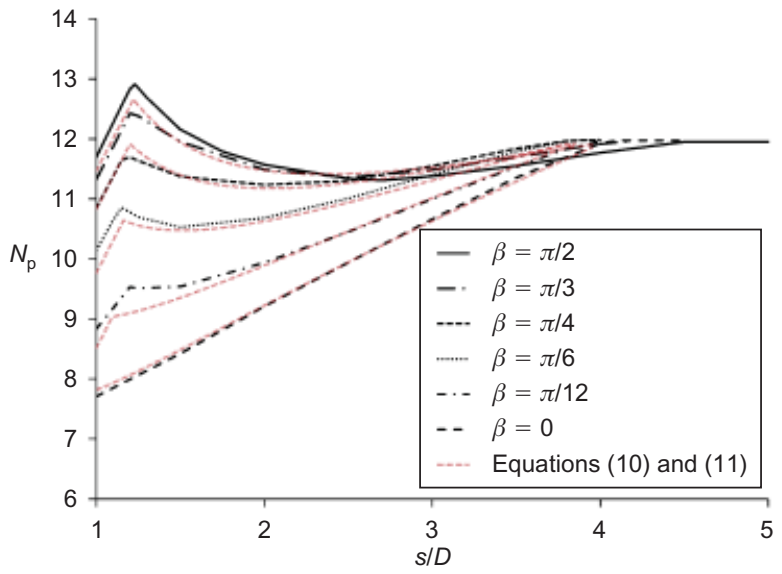

Fig. 9. $N_{\mathrm{p}}$ plotted against $s / D$ relationship from displacement finite-element analyses for $\alpha=1$

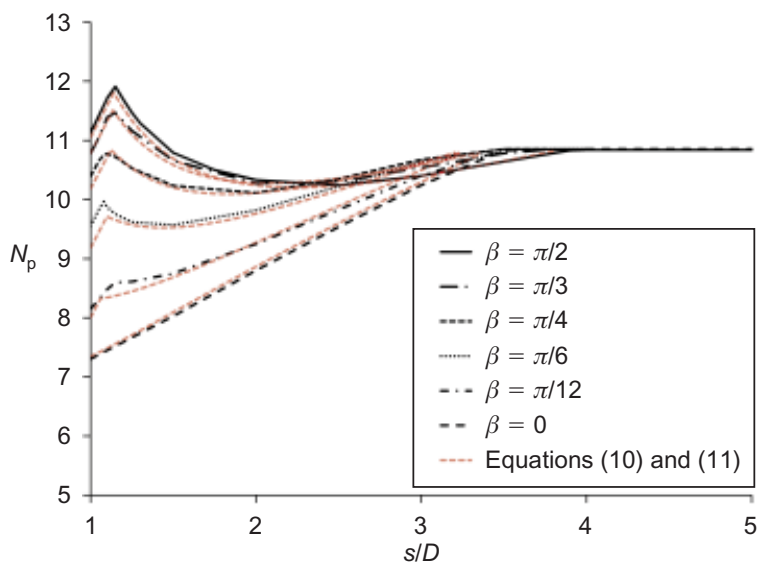

Fig. 10. $N_{\mathrm{p}}$ plotted against $s / D$ relationship from displacement finite-element analyses for $\alpha=0.5$

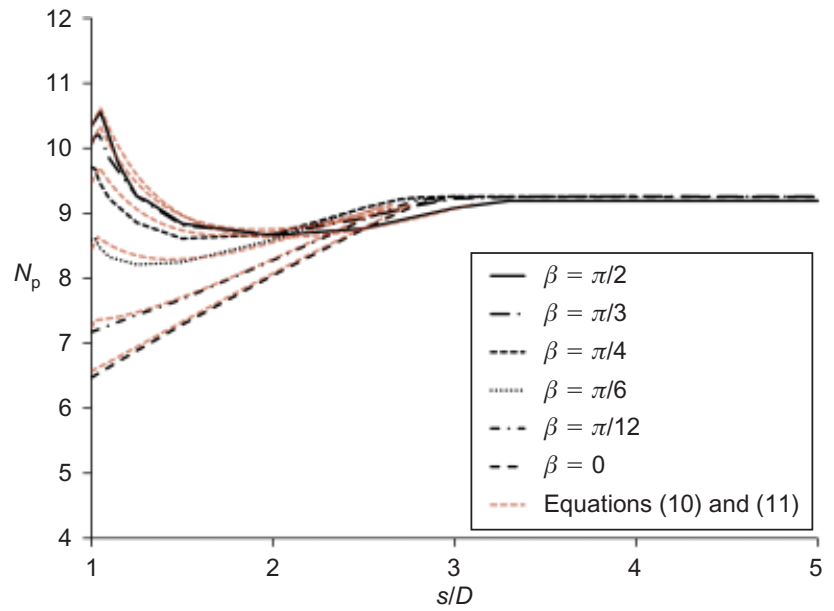

Fig. 11. $N_{\mathrm{p}}$ plotted against $s / D$ relationship from displacement finite-element analyses for $\alpha=0$

$$
\begin{array}{ll}
N_{\mathrm{p}}=N_{\mathrm{p} 0}+\frac{(s / D)-1}{\left(s_{\mathrm{p}} / D\right)-1}\left(N_{\mathrm{pp}}-N_{\mathrm{p} 0}\right) & \text { for } s<s_{\mathrm{p}} \\
N_{\mathrm{p}}=N_{\mathrm{pp}}\left(\frac{s}{s_{\mathrm{p}}}\right)^{b}\left[\frac{N_{\mathrm{p} 1}}{N_{\mathrm{pp}}}\left(\frac{s_{\mathrm{p}}}{s_{1}}\right)^{b}\right]^{\frac{\left(s_{\mathrm{p}} / s\right)-1}{\left(\mathrm{~s}_{\mathrm{p}} / s_{1}\right)-1}} & \text { for } s_{\mathrm{p}} \leqslant s<s_{1}
\end{array}
$$

$N_{\mathrm{p}}$ is equal to the single pile bearing capacity factor $N_{\mathrm{p} 1}$, for $s \geqslant s_{1}$.

However, in this case, the parameters $s_{\mathrm{p}}, s_{1}, N_{\mathrm{p} 0}$ and $b$, which are defined in Fig. 1 and in the notation list, are functions of the displacement angle $\beta$

$$
\begin{aligned}
& s_{\mathrm{p}} / D=1+\left(s_{\mathrm{p}, \pi / 2} / D-1\right) B \\
& s_{1} / D=s_{1, \pi / 2} / D[1-0 \cdot 15 \sin (1 \cdot 5 \beta+\pi / 4)] \\
& N_{\mathrm{p} 0}=N_{\mathrm{p} 0,0}+\left(N_{\mathrm{p} 0, \pi / 2}-N_{\mathrm{p} 0,0}\right) B^{2} \\
& b=\frac{0 \cdot 75}{1+\alpha-(\alpha-0 \cdot 5)(1-B)}
\end{aligned}
$$

where

$$
B=1-(1-2 \beta / \pi)^{3}
$$

$s_{\mathrm{p}, \pi / 2}, \quad s_{1, \pi / 2}$ and $N_{\mathrm{p} 0, \pi / 2}$ are the values of the relevant parameters for $\beta=\pi / 2$

$$
\begin{aligned}
& s_{\mathrm{p}, \pi / 2} / D=1.05+0.18 \alpha \\
& s_{1, \pi / 2} / D=3.1+1.4 \alpha \\
& N_{\mathrm{p} 0, \pi / 2}=10.35+1.4 \alpha
\end{aligned}
$$

$N_{\mathrm{p} 0,0}$ is the value of $N_{\mathrm{p} 0}$ for $\beta=0$

$$
N_{\mathrm{p} 0,0}=8 \cdot 55-2 \mathrm{e}^{-\alpha}
$$

and

$$
N_{\mathrm{pp}}=N_{\mathrm{p} 0}+5 \cdot 4\left(\frac{s_{\mathrm{p}}}{D}-1\right)
$$

The single pile bearing capacity factor $N_{\mathrm{p} 1}$ is given by the lower bound analytical expression of Randolph \& Houlsby (1984)

$$
\begin{aligned}
N_{\mathrm{p} 1}= & \pi+2 \arcsin \alpha+2 \cos (\arcsin \alpha) \\
& +4\left[\cos \left(\frac{\arcsin \alpha}{2}\right)+\sin \left(\frac{\arcsin \alpha}{2}\right)\right]
\end{aligned}
$$

The above equations allow the calculation of the ultimate lateral bearing capacity factor for a given displacement direction $\beta$. However, in most practical cases, the loading direction rather than the displacement direction is known. The calculated failure loads $F_{x}$ and $F_{y}$, parallel $(\beta=0)$ and perpendicular $(\beta=\pi / 2)$ to the pile centre-to-centre axis, respectively, normalised with respect to their ultimate values $F_{x 0}$ (for loading at $\beta=0$ ) and $F_{y 0}$ (for loading at $\beta=\pi / 2$ ), are plotted in Fig. 12. As seen, a unique load interaction curve exists, independent of the value of the adhesion factor, which can be approximated as a circular section

$$
\left(\frac{F_{x}}{F_{x 0}}\right)^{2}+\left(\frac{F_{y}}{F_{y 0}}\right)^{2}=1
$$

Denoting the loading angle as $\beta_{\mathrm{L}}$ and noting that the resultant ultimate load is $F=s_{\mathrm{u}} D N_{\mathrm{p}}$, equation (23) can be rewritten as follows

$$
N_{\mathrm{p}}=\frac{N_{\mathrm{p}\left(\beta_{\mathrm{L}}=\pi / 2\right)} N_{\mathrm{p}\left(\beta_{\mathrm{L}}=0\right)}}{\sqrt{N_{\mathrm{p}\left(\beta_{\mathrm{L}}=\pi / 2\right)}^{2} \cos ^{2} \beta_{\mathrm{L}}+N_{\mathrm{p}\left(\beta_{\mathrm{L}}=0\right)}^{2} \sin ^{2} \beta_{\mathrm{L}}}}
$$

The ultimate lateral bearing capacity factors $N_{\mathrm{p}\left(\beta_{\mathrm{L}}=0\right)}$ and $N_{\mathrm{p}\left(\beta_{\mathrm{L}}=\pi / 2\right)}$ for loading at $\beta_{\mathrm{L}}=\beta=0$ and $\pi / 2$, respectively, can be calculated from equations (10) and (11). 


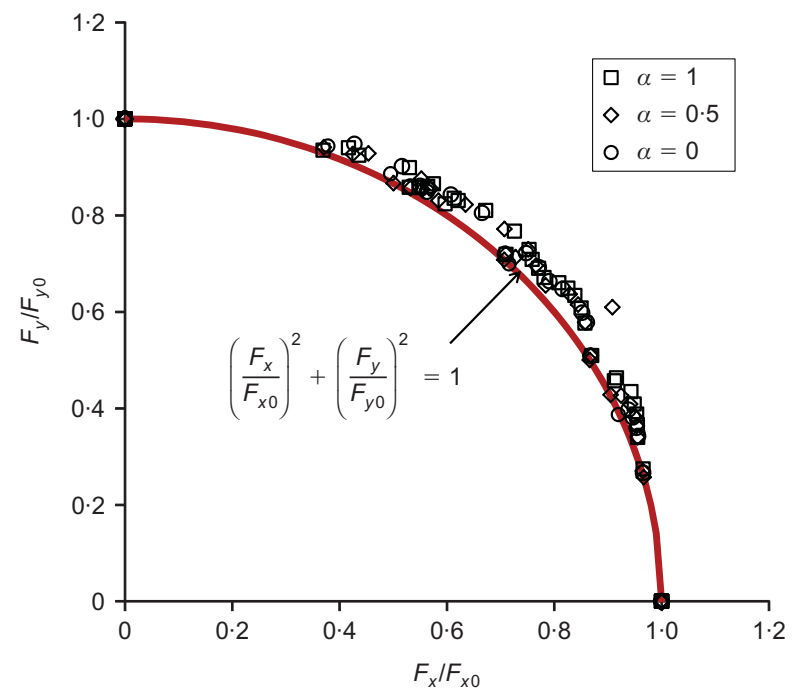

Fig. 12. Relationship between normalised ultimate pile loads

\section{CONCLUSIONS}

Displacement finite-element analyses, finite-element limit analyses and two analytical upper bound solutions were used to calculate the ultimate lateral capacity of two piles loaded parallel to the pile-to-pile axis. The results were used to validate the displacement finite-element model, which was subsequently used to investigate the effect of loading direction on the ultimate pile loads. Based on the finite-element analyses, design equations were proposed which allow the calculation of the undrained ultimate lateral bearing capacity factor of a pile, in a two-pile group, as a function of the pile spacing, the pile-soil adhesion factor and the displacement or the loading direction.

\section{NOTATION}

$B$ function of the angle of displacement

$b$ lateral bearing capacity parameter

$D$ pile diameter

$E_{\mathrm{p}}$ modulus of elasticity of pile

$E_{\mathrm{u}} \quad$ undrained modulus of elasticity

$F_{x}$ component of the failure load in the $x$ direction

$F_{y}$ component of the failure load in the $y$ direction

$F_{x 0}$ ultimate failure load for loading only in the $x$ direction

$F_{y 0}$ ultimate failure load for loading only in the $y$ direction

$N_{\mathrm{p}} \quad$ lateral bearing capacity factor

$N_{\mathrm{pp}}$ peak lateral bearing capacity factor

$N_{\mathrm{p} 0} \quad$ lateral bearing capacity factor for $s=D$

$N_{\mathrm{p} 0,0}$ value of $N_{\mathrm{p} 0}$ for $\beta=0$

$N_{\mathrm{p} 0, \pi / 2}$ value of $N_{\mathrm{p} 0}$ for $\beta=\pi / 2$

$N_{\mathrm{p} 1} \quad$ single pile lateral bearing capacity factor

$N_{\mathrm{p}\left(\beta_{\mathrm{L}}=0\right)}$ lateral bearing capacity factor for loading at $\beta_{\mathrm{L}}=\beta=0$

$N_{\mathrm{p}\left(\beta_{\mathrm{L}}=\pi / 2\right)} \quad$ lateral bearing capacity factor for loading at $\beta_{\mathrm{L}}=\beta=\pi / 2$

$R$ pile radius

$R_{1}, R_{2}$ geometric parameters of mechanism II

\author{
$r$ radial distance from centre of rotation $\mathrm{Y}$ \\ $r^{\prime}$ radius of slip fan \\ $s$ centre-to-centre pile spacing \\ $s_{\mathrm{p}} \quad$ pile spacing corresponding to $N_{\mathrm{pp}}$ \\ $s_{\mathrm{p}, \pi / 2}$ value of $s_{\mathrm{p}}$ for $\beta=\pi / 2$ \\ $s_{\mathrm{u}} \quad$ undrained shear strength \\ $s_{1}$ pile spacing beyond which $N_{\mathrm{p}}=N_{\mathrm{p} 1}$ \\ $s_{1, \pi / 2}$ value of $s_{1}$ for $\beta=\pi / 2$ \\ $v_{\mathrm{o}}$ pile lateral velocity \\ $v, v_{1}, v_{2}, v_{n}, v_{\mathrm{R}}$ internal lateral velocities of failure \\ mechanism \\ $\alpha$ adhesion factor \\ $\beta$ angle of displacement \\ $\Delta W_{\mathrm{p}}$ work done by internal stresses \\ $\delta, \theta, \xi, \theta_{1}, \theta_{2}, \omega$ geometrical optimisation parameters \\ $\theta^{\prime}, \theta_{1}^{\prime}, \theta_{2}^{\prime}, \psi^{\prime}, \omega^{\prime}, \chi$ geometrical parameters \\ $\nu_{\mathrm{p}}$ Poisson ratio of pile \\ $v_{\mathrm{u}}$ undrained Poisson ratio \\ $\tau_{\mathrm{f}}$ ultimate shear stress along discontinuity
}

\section{REFERENCES}

Brinkgreve, R. B. J., Swolfs, W. M. \& Engin, E. (2011). Plaxis 2D 2010 user's manual. Delft, the Netherlands: Plaxis B. V.

Christensen, H. \& Niewald, G. (1992). Laterally loaded piles in clay. Proceedings of the 11th Nordic Geotechnical Meeting, NGM-92, Aalborg, 2, Bulletin 9, pp. 405-410. Lyngby, Denmark: Danish Geotechnical Society.

Georgiadis, K. \& Georgiadis, M. (2012). Development of $p-y$ curves for undrained response of piles near slopes. Comput. Geotech. 40, 53-61.

Georgiadis, K., Sloan, S. W. \& Lyamin, A. V. (2013). Ultimate lateral pressure of two side-by-side piles in clay. Géotechnique 63, No. 9, 733-745, http://dx.doi.org/10.1680/geot.12.P.030.

Klar, A. \& Randolph, M. F. (2008). Upper-bound and load-displacement solutions for laterally loaded piles in clays based on energy minimization. Géotechnique 58, No. 10, 815-820, http:// dx.doi.org/10.1680/geot.2008.58.10.815.

Krabbenhoft, K., Lyamin, A. V., Hjiaj, M. \& Sloan, S. W. (2005). A new discontinuous upper bound limit analysis formulation. Int. J. Numer. Methods Engng 63, No. 7, 1069-1088.

Krabbenhoft, K., Lyamin, A. V. \& Sloan, S. W. (2007). Formulation and solution of some plasticity problems as conic programs. Int. J. Solids Structs 44, No. 5, 1533-1549.

Lyamin, A. V. \& Sloan, S. W. (2002a). Lower bound limit analysis using nonlinear programming. Int. J. Numer. Methods Engng 55, No. 5, 573-611.

Lyamin, A. V. \& Sloan, S. W. (2002b). Upper bound limit analysis using linear finite elements and nonlinear programming. Int. J. Numer. Analyt. Methods Geomech. 26, No. 2, 181-216.

Martin, C. M. \& Randolph, M. F. (2006). Upper-bound analysis of lateral pile capacity in cohesive soil. Géotechnique 56, No. 2, 141-145, http://dx.doi.org/10.1680/geot.2006.56.2.141.

Murff, J. D. \& Hamilton, J. M. (1993). P-Ultimate for undrained analysis of laterally loaded piles. J. Geotech. Engng, ASCE 119, No. 1, 91-107.

Randolph, M. F. \& Houlsby, G. T. (1984). The limiting pressure on a circular pile loaded laterally in cohesive soil. Géotechnique 34, No. 4, 613-623, http://dx.doi.org/10.1680/geot.1984.34.4. 613.

Sloan, S. W. (1988). Lower bound limit analysis using finite elements and linear programming. Int. J. Numer. Analyt. Methods Geomech. 12, No. 1, 61-77.

Sloan, S. W. (1989). Upper bound limit analysis using finite elements and linear programming. Int. J. Numer. Analyt. Methods Geomech. 13, No. 3, 263-282. 